\title{
SEJARAH KOMPUTER
}

\author{
MUHAMMAD ARIF \\ 175100040 \\ Fakultas Komputer \\ Muhammadarif.student@umitra.ac.id
}

\begin{abstract}
Sejarah jaringan komputer bermula dari lahirnya konsep jaringan komputer pada tahun 1940-an di Amerika yang digagas oleh sebuah proyek pengembangan komputer MODEL I di laboratorium Bell dan group riset Universitas Harvard yang dipimpin profesor Howard Aiken. Pada mulanya proyek tersebut hanyalah ingin memanfaatkan sebuah perangkat komputer yang harus dipakai bersama. Untuk mengerjakan beberapa proses tanpa banyak membuang waktu kosong dibuatlah proses beruntun (Batch Processing), sehingga beberapa program bisa dijalankan dalam sebuah komputer dengan kaidah antrian.

Kemudian pada tahun 1950-an ketika jenis komputer mulai berkembang sampai terciptanya super komputer, maka sebuah komputer harus melayani beberapa tempat yang tersedia (terminal), untuk itu ditemukan konsep distribusi proses berdasarkan waktu yang dikenal dengan nama TSS (Time Sharing System). Maka untuk pertama kalinya bentuk jaringan (network) komputer diaplikasikan. Pada sistem TSS beberapa terminal terhubung secara seri ke sebuah komputer atau perangkat lainnya yang terhubung dalam suatu jaringan (host) komputer. Dalam proses TSS mulai terlihat perpaduan teknologi komputer dan teknologi telekomunikasi yang pada awalnya berkembang sendiri-sendiri. Departemen Pertahanan Amerika, U.S. Defense Advanced Research Projects Agency (DARPA) memutuskan untuk mengadakan riset yang bertujuan untuk menghubungkan sejumlah komputer sehingga membentuk jaringan organik pada tahun 1969. Program riset ini dikenal dengan nama ARPANET.
\end{abstract}

Kata Kunci : Sejarah Jaringan Komputer 


\section{A. PENDAhuluan}

B. Pada tahun 1970, sudah lebih dari 10 komputer yang berhasil dihubungkan satu sama lain sehingga mereka bisa saling berkomunikasi dan membentuk sebuah jaringan. Dan pada tahun 1970 itu juga setelah beban pekerjaan bertambah banyak dan harga perangkat komputer besar mulai terasa sangat mahal, maka mulailah digunakan konsep proses distribusi

(Distributed

Processing). Dalam proses ini beberapa host komputer

mengerjakan sebuah pekerjaan besar secara paralel untuk melayani beberapa terminal yang tersambung secara seri disetiap host komputer. Dalam proses distribusi sudah mutlak diperlukan perpaduan yang mendalam antara teknologi komputer dan telekomunikasi, karena selain proses yang harus didistribusikan,

semua host komputer wajib melayani terminal-terminalnya dalam satu perintah dari komputer pusat.

C. Pada tahun 1972, Roy Tomlinson berhasil

menyempurnakan program surat elektonik (email) yang dibuatnya setahun yang lalu untuk ARPANET. Program tersebut begitu mudah untuk digunakan, sehingga langsung menjadi populer. Pada tahun yang sama yaitu tahun 1972, ikon at (@) juga diperkenalkan sebagai lambang penting yang menunjukan "at" atau "pada". Tahun 1973, jaringan komputer $\begin{array}{lr}\text { ARPANET } & \text { mulai } \\ \text { dikembangkan } & \text { meluas ke } \\ \text { luar Amerika } & \text { Serikat. }\end{array}$

Komputer University

College di London merupakan

komputer pertama yang ada di luar Amerika yang menjadi anggota jaringan Arpanet. Pada tahun yang sama yaitu tahun 1973, dua orang ahli komputer yakni Vinton Cerf dan Bob Kahn mempresentasikan sebuah gagasan yang lebih besar, yang menjadi cikal bakal pemikiran International

Network (Internet). Ide ini dipresentasikan untuk pertama kalinya di Universitas Sussex. Hari bersejarah berikutnya adalah tanggal 26 Maret 1976, ketika Ratu Inggris berhasil mengirimkan surat elektronik dari Royal Signals and Radar Establishment di Malvern.

Setahun kemudian, sudah lebih dari 100 komputer yang bergabung di ARPANET membentuk sebuah jaringan atau network.

D.

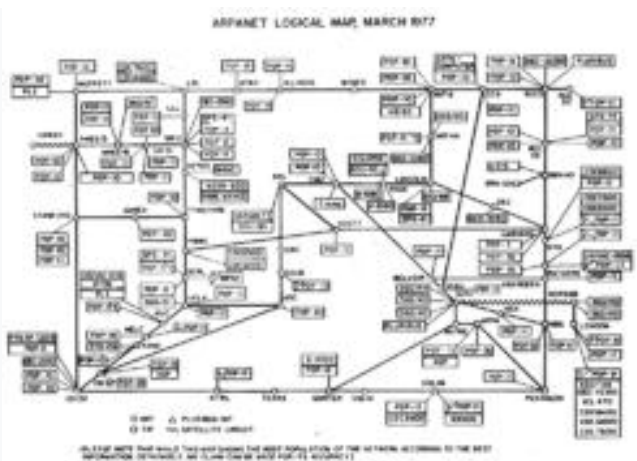

E. Peta logika dari ARPANET

F. Tom Truscott, Jim Ellis dan Steve Bellovin, menciptakan newsgroups perta 


\begin{abstract}
ma yang diberi nama USENET (User

Network) pada tahun 1979.

Tahun 1981, France

Telecom menciptakan sesuatu hal yang baru dengan meluncurkan telepon

televisi pertama, di mana orang bisa saling menelepon yang juga berhubungan dengan video link.
\end{abstract}

G. Seiring dengan bertambahnya komputer yang membentuk jaringan, dibutuhkan sebuah protokol resmi yang dapat diakui dan diterima oleh semua jaringan. Untuk itu, pada tahun 1982 dibentuk sebuah Transmission Control Protocol (TCP) atau lebih dikenal dengan sebutan Internet Protocol (IP) yang kita kenal hingga saat ini. Sementara itu, di Eropa muncul sebuah jaringan serupa yang dikenal dengan Europe Network (EUNET) yang meliputi wilayah Belanda, Inggris, Den mark, dan Swedia. Jaringan EUNET ini menyediakan jasa surat elektronik dan newsgroup USENET

\section{H. PEMBAHASAN / STUDI KASUS}

1. Berdasarkan geografisnya, jaringan komputer terbagi menjadi Jaringan wilayah lokal atau Local Area Network (LAN), Jaringan wilayah metropolitan atau Metropolita $n$ Area Network (MAN), dan Jaringan wilayah luas atau Wide Area Network (WAN). Jaringan wilayah lokal]] merupakan jaringan milik pribadi di dalam sebuah gedung atau tempat yang berukuran sampai beberapa 1 - 10 kilometer. LAN seringkali digunakan untuk menghubungkan komputer-komputer pribadi dan stasiun kerja (workstation) dalam kantor suatu perusahaan atau pabrik-pabrik untuk memakai bersama sumberdaya (misalnya pencetak (printer) dan saling bertukar informasi. Sedangkan Jaringan wilayah metropolitan merupakan perluasan jaringan LAN sehingga mencakup satu kotayang cukup luas, terdiri atas puluhan gedung yang berjarak $10-50$ kilometer. Kabel transmisi

yang digunakan adalah kabel serat optik (Fiber Optic). Jaringan wilayah luas Merupakan jaringan antarkota, antar propinsi, antar negara, bahkan antar benua. Jaraknya bisa mencakup seluruh dunia, misalnya jaringan yang menghubungkan semua bank di Indonesia, atau jaringan yang menghubungkan semua kantor Perwakilan Indonesia di seluruh dunia. Media transmisi utama adalah komunikasi lewat satelit, tetapi banyak yang mengandalkan koneksi serat optik antar negara. 


\section{ID SECURITY}

QWTD4452377-ASP-5244107

\section{J. KESIMPULAN}

Komputer adalah Salah satu alat yang pertama kalinya untuk membantu dalam perhitungan,komputer juga tidak hanya sebagai alat untuk menghitug saja tetapi semua aspek kehidupan dapat dilakukan lebih mudah dan cepat dengan komputer.Dilihat dari generasi ke genarasi juga dari awal generasi pertama sampai sekarang komputer sudah mengalami perkembangan dan perubahan yang cukup pesat,dan komputer dari generasi pertama sampai sekarang lebih semakin canggih lagi yang lebih dapat mengefisien waktu dan biaya.Saat ini unia komputer sudah semakin canggih dengan teknologi baru yang bermunculan dan juga yang ramah lingkungan. laptop merupakan suatu perangkat komputer yang sangat di inginkan bagi kalangan yang berkecimpung atau pengguna IT. Selain dapat digunakan dimana saja dan laptop juga menjadi Gaya Hidup seorang profesional. kemana-mana bisa dibawa dan digunakan.

\section{K. DISKUSI}

Saya bersama teman saya bernama Rudi mendiskusikan tentang contoh ini dengan sangat baik Hasil diskusi dari materi ini adalah ....( minimal 150 kata )

\section{REFERENCE}

[1] O. M. Febriani and A. S. Putra, "Sistem Informasi Monitoring Inventori Barang Pada Balai Riset Standardisasi Industri Bandar Lampung," J. Inform., vol. 13, no. 1, pp. 90-98, 2014.

[2] A. S. Putra, "Paperplain: Execution Fundamental Create Application With Borland Delphi 7.0 University Of Mitra Indonesia," 2018.

[3] A. S. Putra, "2018 Artikel Struktur Data, Audit Dan Jaringan Komputer," 2018.

[4] A. S. Putra, "ALIAS MANAGER USED IN DATABASE DESKTOP STUDI CASE DB DEMOS."

[5] A. S. Putra, "COMPREHENSIVE SET OF PROFESSIONAL FOR DISTRIBUTE COMPUTING."

[6] A. S. Putra, "DATA ORIENTED RECOGNITION IN BORLAND DELPHI 7.0."

[7] A. S. Putra, "EMBARCADERO DELPHI XE 2 IN GPUPOWERED FIREMONKEY APPLICATION."

[8] A. S. Putra, "HAK ATAS KEKAYAAN INTELEKTUAL DALAM DUNIA TEKNOLOGY BERBASIS REVOLUSI INDUSTRI 4.0."

[9] A. S. Putra, "IMPLEMENTASI PERATURAN PERUNDANGAN UU. NO 31 TAHUN 2000 TENTANG DESAIN INDUSTRI BERBASIS INFORMATION TECHNOLOGY."

[10] A. S. Putra, 
"IMPLEMENTATION OF PARADOX DBASE."

A. S. Putra, "IMPLEMENTATION OF

TRADE SECRET CASE STUDY SAMSUNG MOBILE PHONE."

[12] A. S. Putra, "IMPLEMENTATION

PATENT FOR APPLICATION WEB BASED CASE STUDI WWW. PUBLIKLAMPUNG. COM."

[13] A. "IMPLEMENTATION SYSTEM FIRST TO INVENT IN DIGITALLY INDUSTRY."

[14] A. S. Putra, "MANUAL REPORT \& INTEGRATED DEVELOPMENT

ENVIRONMENT BORLAND DELPHI 7.0."

[15] A. S. Putra, "PATENT AS RELEVAN SUPPORT RESEARCH."

[16] A. S. Putra, "PATENT FOR RESEARCH STUDY CASE OF APPLE. Inc."

[17] A. S. Putra, "PATENT PROTECTION FOR APPLICATION INVENT."

[18] A. S. Putra, "QUICK REPORT IN PROPERTY PROGRAMMING."

[19] A. S. Putra, "REVIEW CIRCUIT LAYOUT COMPONENT

REQUIREMENT ON ASUS NOTEBOOK."

[20] A. S. Putra, "REVIEW TRADEMARK PATENT FOR INDUSTRIAL TECHNOLOGY BASED 4.0."

[21] A. S. Putra, "TOOLBAR COMPONENT PALLETTE IN
OBJECT PROGRAMMING."

[22]

A. S. Putra, "WORKING DIRECTORY SET FOR PARADOX 7."

[23] A. S. Putra, "ZQUERY CONNECTION

IMPLEMENTED

PROGRAMMING STUDI CASE PT. BANK BCA Tbk.”

[24] A. S. Putra, D. R. Aryanti, and I. Hartati, "Metode SAW (Simple Additive Weighting) sebagai Sistem Pendukung Keputusan Guru Berprestasi (Studi Kasus: SMK Global Surya)," in Prosiding Seminar Nasional Darmajaya, 2018, vol. 1, no. 1, pp. 85-97.

[25] A. S. Putra and O. M. Febriani, "Knowledge Management Online Application in PDAM Lampung Province," in Prosiding International conference on Information Technology and Business (ICITB), 2018, pp. 181-187.

[26] A. S. Putra, O. M. Febriani, and B. Bachry, "Implementasi Genetic Fuzzy System Untuk Mengidentifikasi Hasil Curian Kendaraan Bermotor Di Polda Lampung," SIMADA (Jurnal Sist. Inf. dan Manaj. Basis Data), vol. 1, no. 1, pp. 21-30, 2018.

[27] A. S. Putra, H. Sukri, and K. Zuhri, "Sistem Monitoring Realtime Jaringan Irigasi Desa (JIDES) Dengan Konsep Jaringan Sensor Nirkabel," IJEIS (Indonesian J. Electron. Instrum. Syst., vol. 8, no. 2, pp. 221-232.

[28] D. P. Sari, O. M. Febriani, and 


\begin{abstract}
A. S. Putra, "Perancangan Sistem Informasi SDM Berprestasi pada SD Global Surya," in Prosiding Seminar Nasional Darmajaya, 2018, vol. 1, no. 1, pp. 289-294.
\end{abstract}

